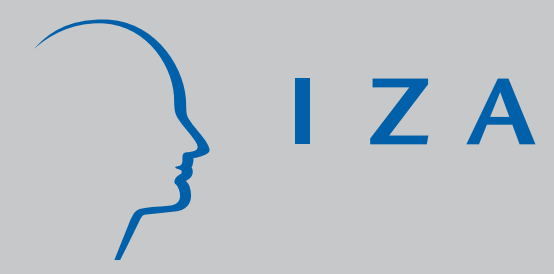

IZA DP No. 3722

Human Capital Investment with Competitive Labor Search

Leo Kaas

Stefan Zink

September 2008 


\title{
Human Capital Investment with Competitive Labor Search
}

\author{
Leo Kaas \\ University of Konstanz \\ and IZA \\ Stefan Zink \\ University of Konstanz
}

\section{Discussion Paper No. 3722 \\ September 2008}

\author{
IZA \\ P.O. Box 7240 \\ 53072 Bonn \\ Germany \\ Phone: +49-228-3894-0 \\ Fax: +49-228-3894-180 \\ E-mail: iza@iza.org
}

Any opinions expressed here are those of the author(s) and not those of IZA. Research published in this series may include views on policy, but the institute itself takes no institutional policy positions.

The Institute for the Study of Labor (IZA) in Bonn is a local and virtual international research center and a place of communication between science, politics and business. IZA is an independent nonprofit organization supported by Deutsche Post World Net. The center is associated with the University of Bonn and offers a stimulating research environment through its international network, workshops and conferences, data service, project support, research visits and doctoral program. IZA engages in (i) original and internationally competitive research in all fields of labor economics, (ii) development of policy concepts, and (iii) dissemination of research results and concepts to the interested public.

IZA Discussion Papers often represent preliminary work and are circulated to encourage discussion. Citation of such a paper should account for its provisional character. A revised version may be available directly from the author. 
IZA Discussion Paper No. 3722

September 2008

\section{ABSTRACT}

\section{Human Capital Investment with Competitive Labor Search ${ }^{*}$}

We study human capital accumulation in an environment of competitive search. Given that unemployed workers can default on their education loans, skilled individuals with a larger debt burden prefer riskier but better paid careers than is socially desirable. A higher level of employment risk in turn depresses the skill premium and the incentives to invest in education. The equilibrium allocation is characterized by too much unemployment, underinvestment by the poor, and too little investment in skill-intensive technologies. A public education system funded by graduate taxes can restore efficiency. More generally, differences in education funding can account for cross-country variations in wage inequality.

JEL Classification: $\quad$ I22, J24, J31

Keywords: directed search, investment, education finance

Corresponding author:

Stefan Zink

University of Konstanz

Department of Economics

Box D 146

D-78457 Konstanz

Germany

E-mail: stefan.zink@uni-konstanz.de

\footnotetext{
* We thank participants in various seminars and conferences for many helpful comments. Support by the German Research Foundation is gratefully acknowledged.
} 


\section{Introduction}

There is some agreement that the average stock of human capital in a society plays an important role in shaping economic development and growth. It is therefore not surprising that economists are interested in possible sources of inefficient schooling decisions and corresponding remedies. Capital market failure has been identified as an important - and perhaps the most important - reason for underinvestment in human capital. It is argued that the poor who have to rely on external sources to pay for education may lack credit opportunities or face worse capital market conditions than the rich and are consequently underrepresented among students. ${ }^{1}$ While contributions supporting this view highlight information frictions in credit arrangements, they put less emphasis on labor market outcomes. Usually a frictionless labor market environment is adopted where all workers find employment at competitive, market-clearing wages. Though this assumption proves convenient analytically, it is far from innocuous because it neglects the interplay between human capital investment and employment prospects. On the one hand, the incidence and duration of unemployment likely affect skill accumulation; since human capital lies idle during unemployment periods, worse employment prospects should be expected to reduce investment incentives. On the other hand, workers' debt positions when leaving school may influence their attitude towards unemployment risk, their career choice, and their search and application behavior.

In this paper we study human capital investment in an environment of labor market imperfections. To minimize deviations from the classical labor market model and still allow for frictions, we develop a competitive search model in the tradition of Moen (1997) where firms post wages and workers direct their search. In our model, poorer workers intending to acquire skills must raise an education loan which they cannot repay during unemployment spells. Although competitive loan premia fully reflect the default risk, the debt position takes an impact on workers' risk-taking behavior. ${ }^{2}$ With a limited liability constraint,

\footnotetext{
${ }^{1}$ Key references are Galor and Zeira (1993), Benabou (1996) and Fernandez and Rogerson (1996).

${ }^{2}$ Student loan default is a relevant issue, particularly in countries with high tuition fees. According to a study of the U.S. Department of Education (Choy and Li (2006)), ten percent of a 1992-1993 cohort of bachelor degree recipients who took out a federal loan had defaulted at least once in the ten years after graduation. Moreover, defaulted student loans cost the
} 
workers with a larger debt burden prefer jobs with higher wages and longer job queues. The labor market in turn provides the risk sought by workers. The equilibrium allocation is characterized by too much unemployment risk among poorer workers which ultimately depresses their return to human capital. When considering their educational options, they anticipate these employment prospects and underinvest in education. As a result, both the educational attainment and the firms' investment in skill-intensive technology are socially too low.

There are no frictions in the credit market in our model, except our natural assumption that loan contracts cannot be contingent on the (unobservable) search behavior in the labor market. As a result, and in contrast to the literature on capital market failure, all workers face the same expected cost of education, regardless of their wealth endowment. On the other hand, the expected skill premium is lower for poorer individuals, so that they do not invest as much as their richer fellows.For rich workers, schooling costs are sunk when they enter the labor market, so they have no impact on their search behavior. By contrast, poorer students who have accumulated debts anticipate that they can default on their loans during longer unemployment spells, avoid repayment, and reduce their effective debt burden. Being less reluctant to accept unemployment risk, they direct their search to riskier and better paid careers. Worse employment prospects, however, diminish their expected skill premium and depress their inclination to invest in human capital.

The extent to which people have to raise debts to pay for their education bears an effect on their labor market behavior and ultimately on their educational attainment. A public education system where society covers individual schooling costs can avoid these distortions and restore efficiency, provided that subsidies are financed completely by a tax on skilled labor. ${ }^{3}$ In this sense, we obtain a justification for public subsidization of higher education, even in the absence of capital market imperfections and human capital externalities. Our mechanism, moreover, suggests that differences in education systems can account for crosscountry variations in wage inequality: both within-group and between-group inequality are larger under private than under public funding. Further, increases

U.S. federal government more than two billion dollars per year during the 1990s (Flint (1997)).

${ }^{3}$ If public education was financed differently, private education costs would become smaller than social costs, so that too many workers would opt for education. Therefore, public education can only implement efficiency if it does not redistribute wealth between different wealth classes. 
in education costs raise inequality under private education, but not under public education.

The remainder of the paper is organized as follows. After a brief review of related literature in the next section, the model is outlined in Section 3, equilibrium in the labor market is characterized in Section 4, and loan market equilibrium and schooling decisions are derived in Section 5. Section 6 analyzes efficiency, and Section 7 discusses public policy and wage inequality. Section 8 extends the inefficiency result to an infinite-horizon model, and Section 9 concludes.

\section{Related literature}

Our paper relates to a larger literature that studies investment behavior under search frictions. Some contributions discuss the hold-up problem which occurs when firms or workers commit to irreversible investment before they meet in the labor market. Under such circumstances agents invest too little since their future trading partners, who benefit from higher investment, cannot be forced to pay an appropriate share in the sunk investment cost. ${ }^{4}$ Another source of underinvestment may come from a coordination problem in a random search environment: every worker benefits from higher education of other workers since a better educated workforce induces higher investment of firms who, at the time of investment, do not know what type of worker they meet (see Acemoglu (1996) and Masters (1998)). However, recent research shows that the presence of competitive forces in the labor market can alleviate these problems. An environment of competitive search where, for example, firms publicly post wages to attract workers, and unemployed workers direct their search to the most attractive firms, can guarantee efficient levels of investment (see, for example, Acemoglu and Shimer (1999b), Shi (2001), Shi (2002) and Rogerson, Shimer, and Wright (2005)). Our paper provides an example showing that underinvestment occurs despite competitive search, with a mechanism that is very different from those of holdup and coordination problems.

There are a few contributions discussing the interrelation between education in-

\footnotetext{
${ }^{4}$ Grout (1984) and Malcomson (1999) discuss the holdup problem in partial worker-firm relationships, Acemoglu and Shimer (1999b) and Acemoglu (2001) examine applications in search models.
} 
vestment and labor market search, but search is random in all of them. ${ }^{5}$ In the models of Moen (1999) and Charlot and Decreuse (2005), workers may invest too much in education since they do not internalize the negative externality of their investment on other workers' employment chances. Such effects are absent from our model since wages under competitive search usually balance all congestion externalities efficiently. Burdett and Smith (2002) and Ortigueira (2006) show that the interaction between endogenous skill formation and labor search can lead to multiplicity of equilibria, some with a combination of too little education and high unemployment. In our model, equilibrium is unique and the mechanism leading to underinvestment does not hinge on complementarities. Closely related to the continuous-time model in Section 8 of this paper is the model of Moen (1998) in which limited liability of borrowers can eliminate the holdup problem and guarantee efficient human capital investment. This result stands in contrast to ours, but it is based on quite different assumptions, in particular an exogenous number of firms and wage bargaining, as we discuss below.

Our mechanism is based on a moral hazard problem which is generated exclusively by search frictions in the labor market. In fact, if the labor market was perfectly competitive, schooling and investment decisions would be efficient. From this perspective, our model is closely related to Acemoglu and Shimer (1999a) who also consider a case of market-generated moral hazard. In their model risk-averse workers aim to reduce unemployment risk and search jobs with too low wages. An unemployment insurance makes workers more willing to accept employment risk and ultimately raises capital-labor ratios and wages. Our paper has risk-neutral workers and does not discuss unemployment insurance; instead the moral hazard problem emerges in the market for education loans. Upon signing a loan contract, workers would prefer to commit to a safer search strategy in the labor market. But since application decisions are private information, the loan contracts cannot be conditioned on it. Limited liability and the lack of commitment ultimately induce workers to behave in a risk-loving way. Clearly, our results also remain intact for moderate degrees of risk-aversion.

\footnotetext{
${ }^{5}$ An exception is Moen and Rosen (2004) who consider a competitive search model where firms can invest in general human capital of their workers and turnover is necessary for efficiency. Equilibrium is constrained efficient if training firms and workers can sign long-term contracts.
} 


\section{The model}

The model has a unit mass of workers, an endogenous large number of firms and a large number of competitive banks. All agents are risk neutral. There is a competitive, frictionless market for education loans, and frictional labor markets for skilled and unskilled workers, both of which are characterized by competitive search. There are two periods. ${ }^{6}$ At $t=0$, some workers obtain education loans from banks, invest in education and become skilled. Workers who do not invest remain unskilled. At $t=1$ firms create jobs for skilled and unskilled workers, they are matched with workers and production takes place. Only employed skilled workers repay their education loans, whilst unemployed skilled workers have zero income and are unable to repay. Under this limited liability constraint, a loan contract is fully specified by the repayment $\rho(\ell)$ of an employed, skilled worker at $t=1$ who had borrowed $\ell>0$ in period $t=0$. Importantly, at what type of job a worker directs his search cannot be observed by banks, so that loan contracts cannot be contingent on the search behavior of workers. We normalize the risk-free interest rate to zero. Perfect competition between risk-neutral banks ensures that the return on an education loan coincides with the risk-free return. That is, the principal $\ell$ must be equal to the repayment $\rho(\ell)$ multiplied with the probability that a worker with loan $\ell$ finds employment, which will be determined below.

Workers are heterogenous along two dimensions, ability and wealth, which are independent. ${ }^{7}$ To simplify the model, ability takes no direct impact on productivity, but it determines a non-pecuniary effort cost $e \geq 0$ that workers must incur upon obtaining education. The differentiable and strictly increasing cumulative distribution function of $e$ is denoted $H$. Let $x \geq 0$ be the wealth level at the beginning of $t=0$. The pecuniary cost of education (tuition) is the same for all workers and equal to $\ell_{0}$. When a worker with wealth $x$ invests in education, he needs to borrow $\ell=\max \left(\ell_{0}-x, 0\right)$. There is a finite number of wealth levels in the population. Let $\Lambda$ denote the cumulative distribution function of $\ell \in\left[0, \ell_{0}\right]$ following from this wealth distribution. To guarantee that some individuals require external funding to pay for their education and some do not, we assume that $0<\Lambda(0)<1$.

\footnotetext{
${ }^{6}$ An infinite-horizon version of our model is presented in Section 8.

${ }^{7}$ The independence assumption simplifies notation but has no effect on results.
} 
Workers consume only in the second period, so they are interested in maximizing their wealth at the end of period 1 net of the effort cost. That is, a worker with effort level $e$, wealth $x$ and $\ell=\max \left(\ell_{0}-x, 0\right)$ obtains utility

$$
\begin{aligned}
U_{s}[\rho(\ell)]+\max \left(x-\ell_{0}, 0\right)-e, & \text { with education, } \\
U_{u}+x & , \text { without education. }
\end{aligned}
$$

Here $U_{s}[\rho(\ell)]$ is the expected income (wage income net of loan repayment) of a skilled worker with loan burden $\rho(\ell)$, and $U_{u}$ is expected income of an unskilled worker, both of which are to be determined below.

At $t=1$ firms enter the labor market and create high-skill and low-skill jobs, both at cost $c$. A high-skill job can only be filled with skilled (educated) workers and produces output $p_{s}$, whereas low-skill jobs can be filled with all workers and produce output $p_{u}<p_{s}$. Below we will impose an assumption guaranteeing that $U_{s}(\rho(\ell))>U_{u}$ for all workers, which makes sure that skilled workers do not apply for low-skill jobs; hence there is no cross-skill matching and markets for skilled and unskilled labor are completely separated.

Matching in the labor market is modelled in the following way. Firms that incurred the entry cost post wages. Having observed all wages, workers decide where to apply, i.e. they seek jobs with a specific wage offered by a firm. ${ }^{8}$ Workers and firms correctly anticipate how workers' application decisions affect their respective matching probabilities. In particular, every wage is associated with an expected number of applicants per job $q=u / v$ ("average queue length"), where $v$ is the number of vacancies posting the same wage and $u$ is the number of workers applying for jobs promising this wage. Let $\varphi(q)$ be the probability that a firm searching in such a submarket is matched with a worker so that $\lambda(q)=\varphi(q) / q$ is the probability that a worker in this submarket finds a job.

Assumption 1 The function $\varphi$ is strictly increasing, strictly concave, differentiable, and it satisfies $\varphi(q) \leq \min (1, q), \varphi^{\prime}(0)=1$, and $\lim _{q \rightarrow \infty} \varphi(q)-q \varphi^{\prime}(q)=1$.

\footnotetext{
${ }^{8}$ The assumption that a worker can direct search to only one wage is clearly restrictive; it relates to the urn-ball microfoundation of matching functions of Montgomery (1991) and Burdett, Shi, and Wright (2001) where a worker sends one application in a given period. Extending such a model to multiple applications, Galenianos and Kircher (2007) show that there is wage dispersion and that workers diversify their application portfolio, and Kircher (2007) considers a related model where equilibrium is constrained efficient. We conjecture, however, that our inefficiency result would carry over to such an environment as well.
} 
The last two requirements imply that $\lambda(0)=1$ and that firms capture all surplus when the number of applicants goes to infinity (Proposition 1 below). Both are not essential but simplify the exposition. A standard example is the urnball matching process which leads to $\varphi(q)=1-e^{-q}$. Another one is $\varphi(q)=$ $q /(1+q)$, which has been called additive-matching-rate technology (see Berentsen, Rocheteau, and Shi (2001)). Matching functions are identical in markets for skilled and unskilled labor. ${ }^{9}$

\section{Competitive search equilibrium}

This section characterizes a competitive search equilibrium at $t=1$ for a given level of education and a distribution of loan contracts. The next section considers equilibrium in the loan market and describes education decisions at $t=0$. Suppose that a mass $E$ of skilled and $1-E$ unskilled workers enter the labor market at $t=1$. Let $F(\rho)$ be the distribution of required loan repayments that educated workers carry into the second period, and let $R$ be the finite support of $F$.

A competitive search equilibrium, conditional on $(E, F)$, is described by the following objects. $\mathcal{W}_{k} \subset \mathbb{R}_{+}, k=s, u$, are sets of posted wages for high-skill and low-skill jobs, the functions $Q_{k}: \mathbb{R}_{+} \rightarrow \mathbb{R}_{+} \cup\{\infty\}, k=s, u$, map wages into average queue lengths, $U_{u} \in R_{+}$is expected income of an unskilled worker, and $U_{s}: R \rightarrow \mathbb{R}_{+}$maps a loan repayment $\rho \in R$ into the expected income of a skilled worker with loan burden $\rho$. We follow Acemoglu and Shimer (1999a) in defining a competitive search equilibrium: ${ }^{10}$

Definition 1 A competitive search equilibrium, conditional on E educated workers and a distribution $F$ of loan repayments, is a list $\left(\mathcal{W}_{s}, \mathcal{W}_{u}, Q_{s}, Q_{u}, U_{s}, U_{u}\right)$ satisfying the following properties:

\footnotetext{
${ }^{9}$ Relaxing the assumption that entry costs and matching functions are identical in both segments of the labor market would only complicate notation without changing any results.

${ }^{10}$ As mentioned before, an assumption below rules out that skilled workers apply for lowskill jobs; hence this possibility is already precluded in our equilibrium definition. Further, the equilibrium definition does not explicitly state how many firms enter in what segment of the labor market and post what wages. These numbers can be traced back from the average queue lengths and the distribution of $\rho$, however.
} 
(a) Firms maximize profits:

$$
\varphi\left[Q_{k}(w)\right]\left(p_{k}-w\right)-c \leq 0
$$

for all $w \geq 0$ and with equality if $w \in \mathcal{W}_{k}, k=s, u$.

(b) Workers' application decisions are optimal. That is, for all $w \geq 0$ and $\rho \in R$,

$$
\begin{array}{ll}
Q_{u}(w) \geq 0 \quad, \quad \lambda\left[Q_{u}(w)\right] w \leq U_{u}, \\
Q_{s}(w) \geq 0 \quad, \quad \max \left\{\lambda\left[Q_{s}(w)\right](w-\rho)-U_{s}(\rho) \mid \rho \in R\right\} \leq 0,
\end{array}
$$

with complementary slackness in (3) and in (4), where

$$
\begin{aligned}
U_{s}(\rho) & =\sup _{w \in \mathcal{W}_{s}} \lambda\left[Q_{s}(w)\right](w-\rho) \\
U_{u} & =\sup _{w \in \mathcal{W}_{u}} \lambda\left[Q_{u}(w)\right] w .
\end{aligned}
$$

In (a), firms trade off a lower wage against a higher probability of finding a worker. Expected profit of a firm in segment $k=s, u$ is maximal when $w \in \mathcal{W}_{k}$, and free entry drives expected profit to zero. Similarly, in (b), workers trade off a higher wage against a lower probability to find a job. Optimal application decisions maximize utility for all types of workers so that (5) and (6) define $U_{s}(\rho)$ and $U_{u}$. The complementary slackness conditions (3) and (4) define queue lengths of all types of workers at arbitrary wages $w \geq 0$, also off the equilibrium. For example, if an unskilled worker can get the job for sure - thus earning $w$ for certain - and still not achieve $U_{u}$, then unskilled workers do not apply for such a vacancy and $Q_{u}(w)=0$. Otherwise, the queue length adjusts such that every applicant expects income $U_{u}$, i.e. $Q_{u}(w)=\lambda^{-1}\left[U_{u} / w\right]$. Similarly, if no skilled worker type can achieve $U_{s}(\rho)$ getting $w-\rho$ for sure - i.e. if $\max \{w-$ $\left.\rho-U_{s}(\rho) \mid \rho \in R\right\}<0-$ then $Q_{s}(w)=0$. If this condition is violated the average queue length of skilled workers at a job posting $w$ guarantees that some types just achieve $U_{s}(\rho)$ while the rest gets less than their maximum utility: $Q_{s}(w)=\lambda^{-1}\left[\min \left\{U_{s}(\rho) /(w-\rho) \mid \rho \in R\right\}\right]$. The following proposition shows that there is a unique competitive search equilibrium.

Proposition 1 Assume that $\max \{\rho \in R\}<p_{s}-c$. 
(a) There exists a unique competitive search equilibrium with the following features:

(i) $\mathcal{W}_{u}=\left\{w_{u}\right\}$ where $w_{u}$ and $q_{u}=Q_{u}\left(w_{u}\right)$ solve $\max _{w, q} \lambda(q) w$ subject to the zero-profit constraint $\varphi(q)\left(p_{u}-w\right)-c=0$, or equivalently

$$
c=\left[\varphi\left(q_{u}\right)-q_{u} \varphi^{\prime}\left(q_{u}\right)\right] p_{u} \quad, w_{u}=p_{u}-\frac{c}{\varphi\left(q_{u}\right)} .
$$

Expected income of an unskilled worker is given by $U_{u} \equiv \lambda\left(q_{u}\right) w_{u}$.

(ii) $\mathcal{W}_{s}=\left\{w_{s}(\rho) \mid \rho \in R\right\}$ where $w_{s}(\rho)$ and $q_{s}(\rho)=Q_{s}\left(w_{s}(\rho)\right)$ solve

$$
\max _{w, q} \lambda(q)(w-\rho)
$$

subject to the zero-profit constraint $\varphi(q)\left(p_{s}-w\right)=c$, or equivalently

$$
c=\left[\varphi\left(q_{s}\right)-q_{s} \varphi^{\prime}\left(q_{s}\right)\right]\left(p_{s}-\rho\right) \quad, w_{s}=p_{s}-\frac{c}{\varphi\left(q_{s}\right)} .
$$

Expected utility as a function of the repayment obligation $\rho$ is given by $U_{s}(\rho) \equiv \lambda\left(q_{s}(\rho)\right)\left(w_{s}(\rho)-\rho\right)$.

(b) The equilibrium wages $w_{s}$ and queue lengths $q_{s}$ are increasing in $\rho$.

(c) Expected labor income $\lambda\left(q_{s}\right) w_{s}$ and expected income net of loan repayment $U_{s}$ are declining in the loan burden $\rho$.

Proof: Appendix.

The first part shows that a wage-risk combination is part of an equilibrium if and only if it maximizes the expected utility of one worker type with a specific repayment obligation subject to a zero-profit constraint for firms. In this sense, the market for skilled labor completely segments into submarkets. This is, of course, a consequence of firms competing for workers by posting wages. Graphically, in Figure 1, the optimum lies at a tangency point between a worker's indifference curve and the zero-profit curve. In particular, workers and firms have the same rate of substitution between $q$ and $w{ }^{11}$ Limited liability, which requires that only employed workers need to repay an education loan (formally embodied in

\footnotetext{
${ }^{11}$ An equivalent formulation states that firms maximize profits $\varphi(q)\left(p_{s}-w\right)$ subject to workers' participation constraint $\lambda(q)(w-\rho)=U(\rho)$, while free entry pins down $q(\rho), w(\rho)$ and $U(\rho)$.
} 
the definition of expected utility (5)), implies that workers with a larger loan burden take higher risks and apply for those jobs that are harder to get. Firms, in turn, recognize the demand for risk and offer those high-wage jobs with a larger number of applicants. ${ }^{12}$ Equations (7) and (8) determine the number of firms in every market segment; the first equation says that firms make zero expected profit (note that a firm receives a fraction $1-\varphi^{\prime}(q) q / \varphi(q)$ of job surplus $p_{s}-\rho, p_{u}$ respectively). The second equation solves the free-entry condition at the corresponding wage.

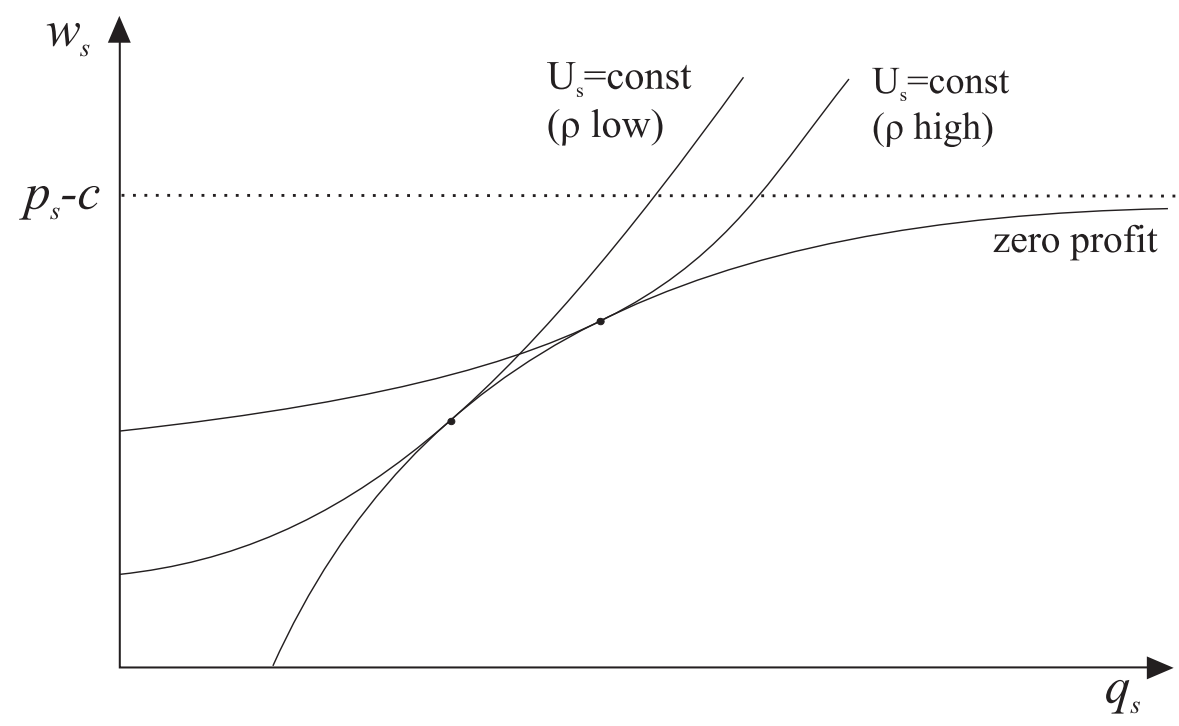

Figure 1: Equilibrium wages and queue lengths for skilled workers. A higher loan burden shifts $w_{s}$ and $q_{s}$ upwards.

Part (c) says that a worker with higher debt earns lower wage income on average, although such a worker applies for jobs with higher wages. Expected income net of loan repayment is also declining in the size of the loan. In particular, workers who can pay education out of their own wealth earn highest expected income.

\footnotetext{
${ }^{12}$ This segmentation cannot occur in a model of random search where wages are the outcome of a bargain after workers and firms meet. In such a model, an increase in $\rho$ raises bargained wages and reduces firm entry which harms employment chances for all workers.
} 


\section{The loan market and education investment}

A large number of risk-neutral banks compete by offering loan contracts specifying for any loan size $\ell$ the repayment in the event of employment, $\rho(\ell)$. For which job a worker applies cannot be observed and thus cannot be specified in the loan contract. However, banks correctly anticipate how the size of the loan affects workers' application behavior. Perfect competition implies that the return on education loans equals the risk-free rate, which is zero, so any equilibrium loan contract must satisfy that $\lambda\left[q_{s}(\rho(\ell))\right] \rho(\ell)=\ell$. Because there may be several loan contracts satisfying this requirement, only the one that maximizes worker utility will be offered in equilibrium:

$$
\rho(\ell)=\underset{\rho}{\operatorname{argmax}}\left\{U_{s}(\rho) \mid \lambda\left[q_{s}(\rho)\right] \rho=\ell\right\} .
$$

Figure 2 shows the equilibrium loan contract for a given loan size $\ell$. The bounded curve is the relation between $\rho$ and $q_{s}(\rho)$ as specified in Proposition 1. Workers without a loan can expect queue length $q_{s}^{0} \equiv q_{s}(0)$, and when $\rho \rightarrow p_{s}-c$, the average queue length goes to infinity, which follows from (8) and Assumption 1. The other curve in the figure is the zero-return relation $\rho=\ell / \lambda(q)$. When the average queue length is zero, an applicant gets the job for sure (Assumption 1), so that $\rho=\ell$ if $q=0$. When $q$ tends to infinity $\lambda$ goes to zero, and $\rho$ tends to infinity. These considerations suggest that there is generically an even number of intersections between these curves. Furthermore, at least one intersection exists provided that $\ell$ is not too large. When $\ell$ is low enough, the curve $\ell / \lambda(q)$ becomes arbitrarily small for all values of $q$ close to $q_{s}^{0}$, so that an intersection with the curve $q_{s}=q_{s}(\rho)$ must exist.

Let $\bar{\ell}$ be the maximum loan size for which there is an intersection between these two curves. Then, for every loan size $\ell \leq \bar{\ell}$, banks offer a loan contract $\rho(\ell)$ which corresponds to the lowest intersection point between the two curves because this is the one where worker utility is largest (Proposition 1 (c)).Figure 2 shows that $\rho(\ell)$ is increasing in $\ell$. We assume that even the poorest workers can find a bank offering an education loan, so there is no credit rationing:

Assumption $2 \ell_{0} \leq \bar{\ell}$. 


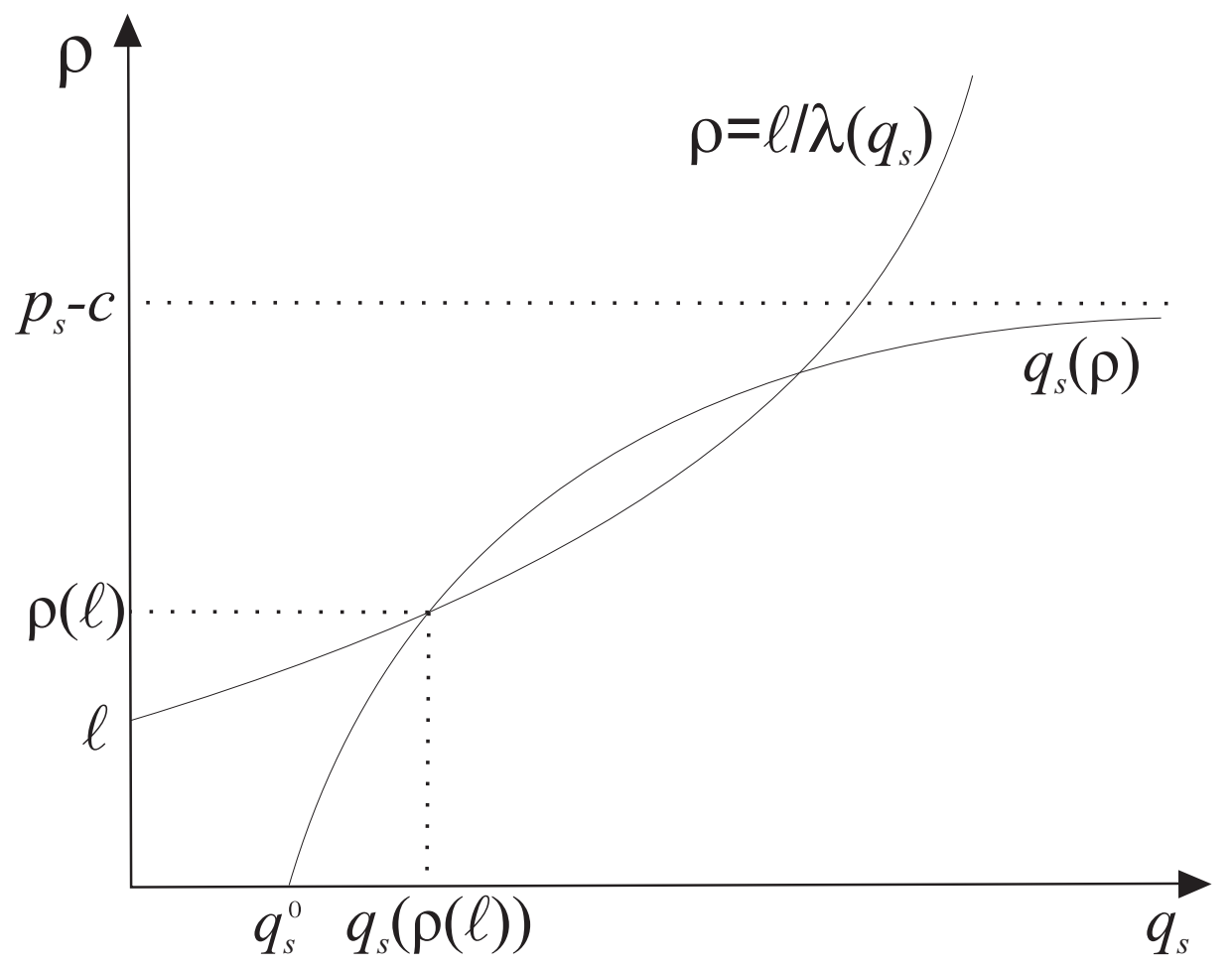

Figure 2: Equilibrium in the loan market.

Proposition 2 Under Assumptions 1 and 2, every worker with $\ell \in\left(0, \ell_{0}\right]$ finds a bank offering a loan contract $\rho(\ell) \geq \ell$. The repayment obligation $\rho$ is increasing in $\ell$ and satisfies $\lim _{\ell \rightarrow 0} \rho(\ell)=0$.

Now consider the education decision. To simplify notation, let

$$
I_{s}(\ell) \equiv \lambda\left[q_{s}(\rho(\ell))\right] w_{s}(\rho(\ell))
$$

be expected labor income of a skilled worker with education loan $\ell$. Propositions 1 and 2 imply that $I_{s}$ is declining in $\ell$. Inserting $\rho(\ell)=\ell / \lambda\left[q_{s}(\rho(\ell))\right]$ into $U_{s}(\rho(\ell))$ shows that expected income of a skilled worker with loan size $\ell$ is

$$
U_{s}(\rho(\ell))=I_{s}(\ell)-\ell
$$

An unskilled worker's expected income is equal to

$$
U_{u}=\lambda\left(q_{u}\right) w_{u} .
$$


A worker with effort level $e$ and loan size $\ell=\max \left\{\ell_{0}-x, 0\right\}$ decides to invest in education if, and only if, utility with education (1) is at least as large as utility without education (2). This condition is equivalent to the requirement that

$$
e+\ell_{0} \leq I_{s}(\ell)-U_{u},
$$

which says that the cost of education (effort and tuition) on the left-hand side is no larger than the expected skill premium on the right-hand side. Importantly, expected education costs do not depend on the level of wealth $x$ : there are no frictions in the loan market (besides our natural assumption that job search behavior is unobservable to creditors), no agent is rationed and all borrowers pay the same (zero) rate of return. Hence the expected (pecuniary) cost of education is equal to $\ell_{0}$ for all workers; since neither banks nor firms make profits in equilibrium, workers must, on average, bear the cost of education. However, wealth affects the size of the education loan and so, via labor market search, the expected skill premium on the right-hand side. Indeed, the expected skill premium is increasing in the level of wealth. Poorer workers with a larger debt burden take higher risks, achieving a lower income in expectation.

Because $I_{s}$ is falling in $\ell$, there is a declining curve in $(e, \ell)$-space, separating investors from noninvestors, as shown in Figure 3. Clearly, individuals with higher ability (who have lower $e$ ) or who are richer (a lower $\ell$ ) are those who invest in education. We assume that the poorest workers invest in education, provided they are clever enough:

Assumption $3 I_{s}\left(\ell_{0}\right)-U_{u}>\ell_{0}$.

The assumption implies that there are critical effort levels $0<\underline{e}<\bar{e}$ such that all workers with $e \leq \underline{e}$ invest and no worker with $e>\bar{e}$ invests. Assumption 3 also implies that expected income of the poorest skilled worker is strictly larger than expected income of an unskilled worker, i.e. $U_{s}\left(\rho\left(\ell_{0}\right)\right)=I_{s}\left(\ell_{0}\right)-\ell_{0}>U_{u}$. In particular, all skilled workers obtain strictly higher utility when applying for a high-skill job rather than applying for a low-skill job. This justifies the implicit simplifying assumption underlying the definition of a competitive search equilibrium in Section 3.

From (10) and $e \sim H$, the number of educated persons with loan size $\ell$ is $H\left[I_{s}(\ell)-U_{u}-\ell_{0}\right]$. This implies 


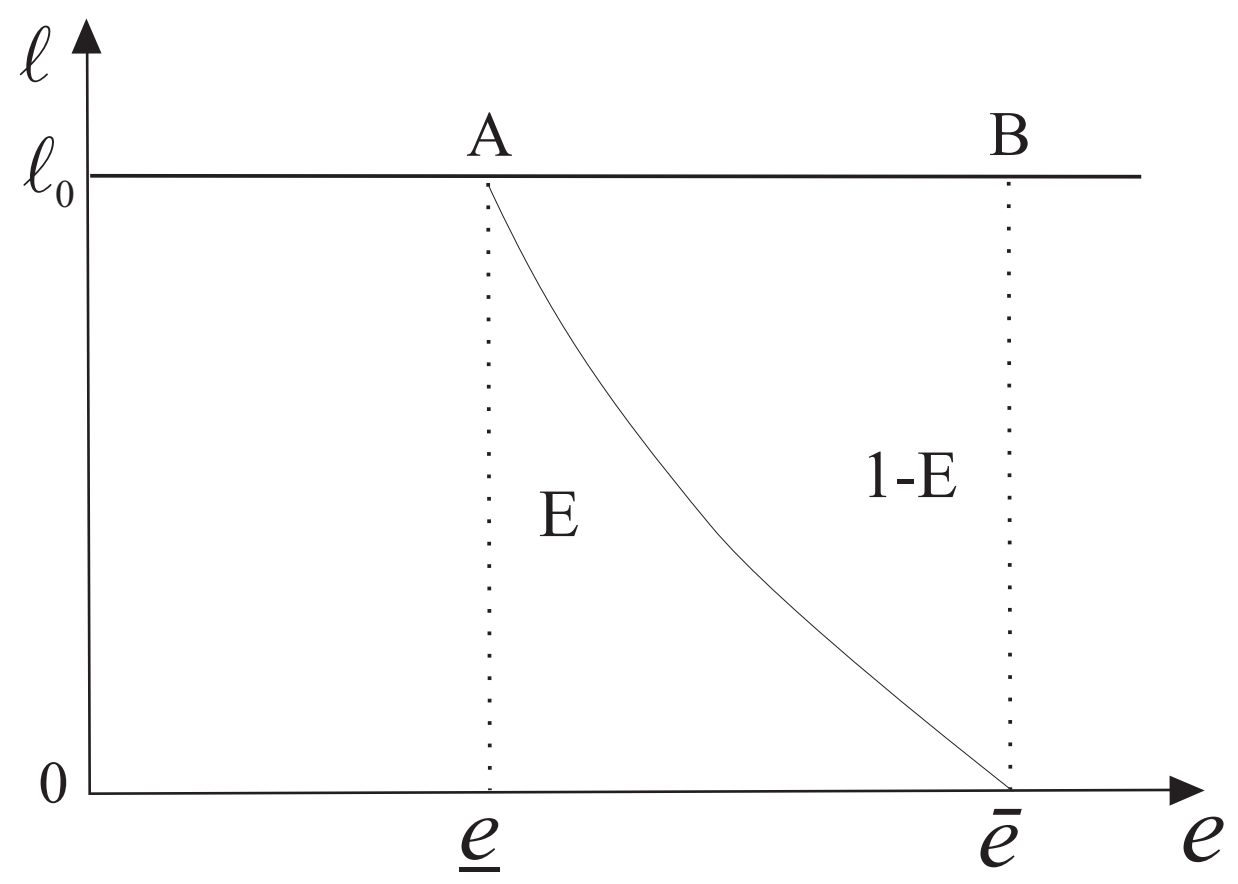

Figure 3: The sets of investing and non-investing individuals are separated by the line $A \bar{e}$.

Proposition 3 Under Assumptions 1-3, there exists an equilibrium where

$$
E=\int_{0}^{\ell_{0}} H\left[I_{s}(\ell)-U_{u}-\ell_{0}\right] d \Lambda(\ell)
$$

workers invest in education. The numbers of low-skill and high-skill jobs are $J_{u}=(1-E) / q_{u}$ and

$$
J_{s}=\int_{0}^{\ell_{0}} \frac{H\left[I_{s}(\ell)-U_{u}-\ell_{0}\right]}{q_{s}(\rho(\ell))} d \Lambda(\ell) .
$$

\section{Inefficiency}

Consider a central planner who cannot overcome search frictions but who can dictate which workers obtain education and how many firms enter what segment of the labor market. Clearly, the planner does not care about the distribution of wealth. He simply decides a cutoff level of effort $e^{P}$ (so that all workers with $e \leq e^{P}$ invest) and the number of firms in the two segments which are $H\left(e^{P}\right) / q_{s}^{P}$ 
and $\left(1-H\left(e^{P}\right)\right) / q_{u}^{P}$, where $q_{s}^{P}$ and $q_{u}^{P}$ are the corresponding queue lengths. The planner is interested in maximizing aggregate surplus which is total output net of the cost of education (pecuniary and non-pecuniary) and net of job-creation costs:

$H(e) \lambda\left(q_{s}\right) p_{s}+(1-H(e)) \lambda\left(q_{u}\right) p_{u}-c\left[\frac{H(e)}{q_{s}}+\frac{1-H(e)}{q_{u}}\right]-H(e) \ell_{0}-\int_{0}^{e} e^{\prime} d H\left(e^{\prime}\right)$.

Maximization with respect to $e, q_{s}$ and $q_{u}$ yields the following result.

Proposition 4 Let $\left(q_{s}(),. q_{u}, E, J_{s}, J_{u}\right)$ be the competitive equilibrium of Proposition 3 and let $\left(q_{s}^{P}, q_{u}^{P}, E^{P}, J_{s}^{P}, J_{u}^{P}\right)$ be the social optimum. Then,

(a) $q_{u}^{P}=q_{u}, q_{s}^{P}=q_{s}(0)<q_{s}(\rho)$ for all $\rho>0$.

(b) there is too little investment in education, $E<E^{P}=H\left(e^{P}\right)$, the number of high-skill jobs is too low, $J_{s}<J_{s}^{P}$, and the number of low-skill jobs is too high, $J_{u}>J_{u}^{P}$.

Proof: Appendix.

Part (a) of the proposition compares the socially optimal queue lengths with those in the competitive equilibrium. In the market for unskilled labor, competitive search produces the right queue length, i.e. entry is efficient conditional on the number of unskilled workers. This result is little surprising and simply establishes the finding of Moen (1997) that competitive search leads to efficient firm entry. However, queue lengths in submarkets for skilled workers with education loans are too long. This inefficiency reflects the moral hazard problem that is generated by search frictions. Banks offer contracts which take into account the default risk but which cannot commit workers to a certain search strategy in the labor market. To reduce default, banks would like to induce workers to seek jobs with lower wages and shorter job queues. Workers, however, can evade repayment during unemployment, so they prefer to search for high-wage jobs with longer queues. In equilibrium, thus, job queues are too long and default is too high.

Part (b) compares socially optimal investment with investment in the competitive equilibrium. There is too little investment in education and too little investment in high-skill technology. In fact, those workers with $\ell>0$ and $e \in\left(I_{s}(\ell)-U_{u}-\ell_{0}, \bar{e}\right]$ (the triangle $A B \bar{e}$ in Figure 3) do not invest although 
it would be socially beneficial if they did. Lastly, since market tightness is efficient in the unskilled sector, there are too many low-skill jobs together with too many unskilled workers.

To understand why there is too little investment in education, observe first that the expected cost of education is the same for all workers, regardless of their initial wealth. Therefore the private cost of education coincides with the social cost. In this respect, our inefficiency is quite different from alternative stories explaining insufficient investment by imperfections in the capital market which make borrowing for poor individuals too expensive (or even impossible). The reason why fewer poor individuals invest in our model is precisely that their average queue lengths are too high which ultimately leads to a skill premium which is too low relative to the output gain for society. Put differently, utilization of human capital is too low for poorer individuals.

It is also important to emphasize that the underinvestment result is quite different from the usual holdup effect which says that workers invest too little in education because firms gain part of the return while only workers bear the cost. Here, again, workers bear the education cost alone, but firms do not benefit from education. Instead, they offer higher wages, and because they do, there is too little entry which ultimately depresses the private return to education.

The negative dependence of the skill premium on $\ell$ would disappear if workers could commit to a search behavior in the labor market at the time when the loan contract is signed. In this sense, moral hazard and the lack of commitment are at the heart of the problem. Firms service workers' preferences by providing highwage jobs associated with higher unemployment risk. Our model is therefore characterized by market-generated moral hazard: if the labor market did not supply the corresponding wage/risk combinations, workers could not apply for these jobs.

A similar problem of market-generated moral hazard is studied in Acemoglu and Shimer (1999a). They consider a model with risk-averse workers who do not differ in their skill level and wish to insure against labor market risk. Firms supply low-wage/low-unemployment jobs, and the labor market displays inefficiently low risk-taking together with insufficient investment. Acemoglu and Shimer show that a moderate unemployment insurance increases workers' willingness to accept risk which raises investment and output. Introducing risk aversion in our model 
would reduce the equilibrium amount of uncertainty, thus counteracting the effect described above. In fact, it can be shown that any concave transformation of the utility function leads to lower $q$ and lower $w \cdot{ }^{13}$ Whether the model produces more or less than the output-maximizing amount of risk cannot be decided in general. For a moderate degree of risk aversion, however, the limited liability effect would dominate, so that there is too much risk-taking and too little investment in education in the aggregate. When risk aversion increases, employment uncertainty declines and investment goes up.

\section{$7 \quad$ Public policy and wage inequality}

What can policy do to restore efficiency? One possibility implementing the efficient allocation is a public education system which is financed by a tax on skilled labor (a "graduate tax"). Suppose the government pays the education cost $\ell_{0}$ for every worker who wants to become educated, which is financed by a tax $t$ on the wage income of skilled workers. Such a proportional tax on skilled labor does not distort the competitive search equilibrium. Indeed, expected utility of a skilled worker searching a job $(w, q)$ is $\lambda(q) w(1-t)$, and maximization of this expression subject to the zero-profit constraint $c=\varphi(q)\left(p_{s}-w\right)$ is independent of $t$, implementing the efficient queue length $q_{s}^{P}=q_{s}(0)$ together with the skilled wage $w_{s}^{P} \equiv p_{s}-c / q_{s}^{P}$. The specification that only skilled workers pay for education also guarantees that education decisions are efficient. Intuitively, with public education private (pecuniary) education costs are zero while the social education costs are still at $\ell_{0}$. To make sure that not too many workers invest, the expected skill premium must be reduced by exactly $\ell_{0}$. Formally, the government budget is balanced if the expected tax revenue of every skilled worker is equal to the worker's education expense, i.e.

$$
t \lambda\left(q_{s}^{P}\right) w_{s}^{P}=\ell_{0}
$$

But precisely this condition makes sure that all workers with $e \leq \bar{e}=e^{P}$, and only those, invest in education. In fact, a worker opts for education whenever the

\footnotetext{
${ }^{13} \mathrm{~A}$ formal proof is based on an application of a revealed preference argument as in Acemoglu and Shimer (1999a).
} 
net skill premium is at least as large as the effort cost:

$$
e \leq \lambda\left(q_{s}^{P}\right) w_{s}^{P}(1-t)-U_{u}=U_{s}(0)-\ell_{0}-U_{0}=e^{P}
$$

These considerations also show that public education can only implement an efficient allocation if it is completely financed by a tax on skilled labor. Any other way of financing public education, for example by partly taxing wealth or unskilled labor, would lead to overeducation: the skill premium would become larger than the education cost of the efficient marginal worker.

Proposition 5 Public education financed with a proportional graduate tax implements the efficient outcome. Any form of financing where unskilled workers pay some share of public education leads to overeducation.

Since a graduate tax works similarly as a progressive income tax, our result relates to Bovenberg and Jacobs (2005) who argue that progressive taxation and education subsidies are Siamese twins. If the government taxes skilled labor to redistribute income towards the less able, subsidies should be introduced to keep human capital at an efficient level. Our argument goes the other way round. Debt financed education leads to an inefficiently low level of human capital, and subsidies help avoiding these distortions. A tax on skilled labor must then be used to limit investment activity.

Another policy implementing the same efficient outcome would be a more flexible graduate tax system in which the government pays any required level of education expenses $\ell=\max \left\{\ell_{0}-x, 0\right\}$, and skilled workers pay a tax on labor income, where the individual tax rate $t_{\ell}$ depends on $\ell$. Again, the budget is balanced and education investment is efficient if the government subsidy is exactly offset by the expected tax payment, $\ell=t_{\ell} \lambda\left(q_{s}^{P}\right) w_{s}^{P}$, so that the expected pecuniary cost of education is $\ell_{0}$ for all workers. Put differently, the policy will only implement an efficient allocation if it is free from any redistribution between different wealth classes. Again, this contrasts with models of capital market failure, which typically suggest a redistribution of wealth from richer to poorer households as a means to raise welfare. ${ }^{14}$

\footnotetext{
${ }^{14}$ Instead of paying for education directly, the government might subsidize private loans by guaranteeing repayment in case of unemployment. While such a measure would reduce the risk premium - loans are paid back regardless of the employment status - and the repayment obligation, search/application behavior would still be distorted: agents have an incentive to choose too much risk because some of the debt costs are now borne by society.
} 
Economies with public and private education regimes not only differ in their relative supply of skills, they also differ in wage inequality, both between groups and within groups. In a simple supply-demand framework, a larger relative supply of skilled labor tends to depress the skill premium. However, such an effect is absent in our model, where the marginal product of skilled and unskilled labor is constant and where, as in other search models, free entry ensures that any change in the supply of labor raises the number of jobs proportionately with no effect on wages. Nevertheless, private education has larger wage inequality than public education, even in the absence of a difference in the supply of skills. Under public education, all skilled workers earn the same wage $w_{s}(0)$; hence there is no within-group wage inequality, and the measured skill premium is simply $w_{s}(0)-w_{u} \cdot{ }^{15}$ Under private education, only some workers earn $w_{s}(0)$, but there are others who earn higher wages $w_{s}(\rho)>w_{s}(0)$. Hence, within-group wage inequality is positive, and the measured skill premium, which is the difference between the average of $w_{s}(\rho)$ across all employed, skilled worker and $w_{u}$, is larger than $w_{s}(0)-w_{u}$. This shows

Proposition 6 An economy with private education has larger within-group wage inequality and a larger skill premium than an identical economy with public education.

One may wonder whether our model can qualitatively account for the diverging trends in wage inequality between the USA and several European countries during the last decades. Many contributions explaining this phenomenon argue that Europe's rigid labor markets prevented wage inequality from rising as much as in the USA, or have contributed to less skill-biased technical change in Europe (see for example Acemoglu (2003)). Our model can deliver an alternative story which is based on differences in education finance, instead of differences in labor market institutions. To abstract from changes in the relative supply of skills, suppose that there are only two ability levels and two wealth classes: some agents have $e=0$ and always educate while others have very high $e$ and never educate. On the other hand, some have high wealth and do not need to borrow, while others have no wealth and need to borrow $\ell_{0}$ to obtain education. In this setting,

\footnotetext{
${ }^{15}$ The way how public education is financed takes no impact on wages, as long as taxes on labor income are proportional.
} 
moderate changes in education costs take no impact on skill supply. They also take no impact on wage inequality under public educations, but they alter the skill premium and within-group wage inequality under private education. Although definite results are hard to derive analytically, all our numerical experiments show that both inequality measures are increasing in $\ell_{0} \cdot{ }^{16}$ Hence, a noticeable increase in tuition (as it occurred in the USA during the last decades) can trigger a rise in wage inequality in a private education regime. Under public education, in contrast, an increase in $\ell_{0}$ together with an increase of (proportional) taxes has no effect on wage inequality.

\section{An infinite-horizon model}

The previous discussion has focused on a two-period setting where every individual can be in only two states in the second period; either the worker finds a job and honors his obligations, or he is unemployed and defaults. The presence of limited liability leads to a preference for risk among borrowers which ultimately depresses human capital investments. A similar mechanism is at work in a multiperiod model, provided that the length of unemployment spells takes an impact on the effective debt burden. Then again, agents with a larger debt search for better-paid jobs at the expense of longer-lasting unemployment. We illustrate this assertion with a simple infinite-horizon model where debtors, whilst being unemployed, are able to defer repayment and to reduce the effective debt burden. ${ }^{17}$ Indeed, it is common practice in some countries to provide students with subsidized loans which do not accumulate interest when payments are deferred during unemployment spells (e.g. Federal Stafford Loans in the USA). To give another example, many German banks require a mandatory residual debt insurance (covering the risk of unemployment, among others) upon granting an education

\footnotetext{
${ }^{16}$ When $\ell_{0}$ goes up, $\rho(\ell)$ is increasing, and so are wages $w_{s}(\rho(\ell))$. However, since $q_{s}(\rho(\ell))$ is falling, fewer workers earn high wages, so that the net effect on the mean skilled wage and on residual inequality is generally ambiguous. However, all our numerical experiments with an urn-ball matching function showed that these inequality measures are globally increasing in $\ell_{0}$.

${ }^{17}$ More generally, "unemployment" need not literally refer to a situation where a person is not working. In many loan arrangements, debt can be deferred when income is low which may also result from a low-skill employment status. Indeed, our mechanism should work equally in an alternative setting with a competitive low-skill labor market where every educated worker can find employment.
} 
loan. Further, the possibility of consumer bankruptcy also facilitates default as a potential consequence of unemployment.

The model is set in continuous time. During every unit time interval a cohort of size $\delta$ is born, and all individuals face a flow probability $\delta$ of death (or permanent labor market exit), so that the size of the working population stays constant at one. Upon birth, agents decide whether to invest in education which costs effort $e$ and a fixed investment of resources $\ell_{0}$. As before, $e$ has distribution function $H$ in every cohort, but now all agents start life with zero wealth; hence every agent opting for education must take an education loan of size $\ell_{0}$. Education is not timeconsuming and happens instantaneously. After the education decision, workers search for jobs and start producing once they are matched with firms. The flow probabilities with which firms encounter workers and workers meet firms, $\varphi$ and $\lambda$, are derived from a constant-returns, concave matching technology satisfying the Inada conditions. To simplify things, we abstain from job destruction, so job separations occur only if the worker exits the labor market. In this event the vacancy becomes worthless.

To further simplify, we follow Moen (1998) and consider only annuity contracts specifying a constant flow repayment which is independent of the individual repayment history. ${ }^{18}$ The repayment may however depend on the employment status of workers; hence any contract specifies flow repayment during employment and unemployment, $\rho^{E}$ and $\rho^{U}$. A contingent contract has zero repayment during unemployment, $\rho^{U}=0$. With such a contract, the effective debt burden is declining in the length of the unemployment spell, a feature which is embodied in many education loan arrangements, as mentioned above. As in the static case, contingent loans generate incentives to search for high-wage jobs, thus accepting longer unemployment on average. In contrast, an uncontingent contract specifies a repayment which does not depend of the employment status, $\rho^{E}=\rho^{U}$. Here, the effective debt burden is independent of the duration of unemployment. In both scenarios, the banking sector is perfectly competitive. Loan repayment flows are determined so that the expected discounted value of the payment stream equals the loan size $\ell_{0}$. This is equivalent to the requirement that a loan contract promises the same expected return as risk-free investment, whose return is

\footnotetext{
${ }^{18} \mathrm{~A}$ more realistic setup where workers repay the exact principal plus accumulated interest complicates the model considerably since one would need to keep track of the distribution of debt across different cohorts.
} 
denoted $r$.

At every instant, firms create high-skill and low-skill jobs and start looking for a suitable worker. Job creation costs fixed investment $c$ which must be incurred upfront. Free entry ensures that the discounted value of expected profits of a vacancy equals $c$. We proceed to characterize the labor market equilibrium for a given loan contract $\left(\rho^{U}, \rho^{E}\right)$.

The asset values of unemployed and employed skilled persons satisfy the Bellman equations

$$
\begin{aligned}
& r U_{s}=-\rho^{U}+\lambda\left(q_{s}\right)\left(E_{s}-U_{s}\right)-\delta U_{s}, \\
& r E_{s}=-\rho^{E}+w_{s}-\delta E_{s} .
\end{aligned}
$$

Combining yields

$$
U_{s}=\frac{-\rho^{U}(r+\delta)+\lambda\left(q_{s}\right)\left[w_{s}-\rho^{E}\right]}{(r+\delta)\left[r+\delta+\lambda\left(q_{s}\right)\right]} .
$$

Similarly the asset values of filled and vacant high-skill jobs satisfy

$$
\begin{aligned}
& r F_{s}=p_{s}-w_{s}-\delta F_{s} \\
& r V_{s}=\varphi\left(q_{s}\right)\left(F_{s}-V_{s}\right)
\end{aligned}
$$

which yields

$$
V_{s}=\frac{\varphi\left(q_{s}\right)\left[p_{s}-w_{s}\right]}{(r+\delta)\left(r+\varphi\left(q_{s}\right)\right)} .
$$

We need to determine the equilibrium values of $w_{s}$ and $q_{s}$. Applying a similar notion of competitive search equilibrium as in the two-period version, the equilibrium maximizes workers' utility subject to a zero-profit condition for firms (cf. Proposition 1 and Moen (1997)). The skilled wage $w_{s}$ and the queue length $q_{s}$ are therefore chosen to maximize $U_{s}$ s.t. $V_{s}=c$. Inserting $w_{s}$ from this constraint into $U_{s}$ and using $\varphi\left(q_{s}\right)=\lambda\left(q_{s}\right) q_{s}$ allows us to write this problem as

$$
\max _{q_{s}} \frac{\lambda\left(q_{s}\right) p_{s}-(r+\delta)\left[r / q_{s}+\lambda\left(q_{s}\right)\right] c-\rho^{U}(r+\delta)-\lambda\left(q_{s}\right) \rho^{E}}{(r+\delta)\left[r+\delta+\lambda\left(q_{s}\right)\right]} .
$$

Note at this point that for $\rho^{E}=\rho^{U}$ the solution to this problem does not depend on $\rho^{E}$. In particular, $U_{s}$ can then be written as

$$
U_{s}=\frac{\lambda\left(q_{s}\right) p_{s}-(r+\delta)\left(r / q_{s}+\lambda\left(q_{s}\right)\right) c}{(r+\delta)\left[r+\delta+\lambda\left(q_{s}\right)\right]}-\frac{\rho^{E}}{r+\delta},
$$


so that $q_{s}$ simply maximizes the first term in this expression.

In the general case which admits $\rho^{E} \neq \rho^{U}$, a necessary and sufficient condition for an optimum is given by

$$
\left[\varphi\left(q_{s}\right)-q_{s} \varphi^{\prime}\left(q_{s}\right)\right]\left[p_{s}-\left(\rho^{E}-\rho^{U}\right)-(r+\delta) c\right]=r c\left[r+\delta+\varphi^{\prime}\left(q_{s}\right)\right]
$$

While the right-hand side of (14) is strictly decreasing in $q_{s}$, the left-hand side is strictly increasing. Because of the Inada conditions for $\varphi$, there exists a unique solution $q_{s}^{M}$. It is obvious that $q_{s}^{M}$ is independent of $\rho^{E}$ for $\rho^{E}=\rho^{U}$ and strictly increasing in $\rho^{E}-\rho^{U}>0$.

Perfect bank competition guarantees that the present discount value of loan repayment is equal to the loan size $\ell_{0}$. Let $A^{E}\left(A^{U}\right)$ denote the asset value of debt when the debtor is currently employed (unemployed). These values satisfy the arbitrage conditions

$$
r A^{E}=\rho^{E}-\delta A^{E} \quad \text { and } \quad r A^{U}=\rho^{U}+\lambda\left(A^{E}-A^{U}\right)-\delta A^{U} .
$$

Since every newly educated workers is unemployed, perfect competition between banks implies that $A^{U}$ equals $\ell_{0}$. Using (15) yields the following relation between $\rho^{E}$ and $\rho^{U}$ :

$$
\rho^{U}(r+\delta)+\lambda \rho^{E}=(r+\delta+\lambda)(r+\delta) \ell_{0}
$$

For an uncontingent loan we obtain $\rho^{E}=\rho^{U}=(r+\delta) \ell_{0}$, i.e. the annuity is discounted with the sum of the risk-free rate and the exit rate. With a contingent loan $\left(\rho^{U}=0\right)$, the repayment rate for the employed is

$$
\rho^{E}=\frac{(r+\delta)(r+\delta+\lambda)}{\lambda} \ell_{0}>(r+\delta) \ell_{0}
$$

Making use of (16), the equilibrium utility of an unemployed skilled person can be written as

$$
U_{s}^{*}\left(\rho^{E}-\rho^{U}\right)=\frac{\lambda\left(q_{s}^{M}\right) p_{s}-(r+\delta)\left(r / q_{s}^{M}+\lambda\left(q_{s}^{M}\right)\right) c}{(r+\delta)\left[r+\delta+\lambda\left(q_{s}^{M}\right)\right]}-\ell_{0} .
$$

Comparison of (13) and (17) shows that $U_{s}^{*}$ is maximal when $\rho^{E}-\rho^{U}=0$. For any $\rho^{E} \neq \rho^{U}, U_{s}^{*}$ is smaller since $q_{s}^{M}$ maximizes the expression (12), but not (13). Consequently, $U_{s}^{*}(0)>U_{s}^{*}\left(\rho^{E}-\rho^{U}>0\right)$. 
Similarly, utility of an unskilled, unemployed worker can be calculated as

$$
U_{u}^{*}=\frac{\lambda\left(q_{u}^{M}\right) p_{u}-(r+\delta)\left(r / q_{u}^{M}+\lambda\left(q_{u}^{M}\right)\right) c}{(r+\delta)\left[r+\delta+\lambda\left(q_{u}^{M}\right)\right]}
$$

where $q_{u}^{M}$ solves

$$
\left[\varphi\left(q_{u}^{M}\right)-q_{u}^{M} \varphi^{\prime}\left(q_{u}^{M}\right)\right]\left[p_{u}-(r+\delta) c\right]=r c\left[r+\delta+\varphi^{\prime}\left(q_{u}^{M}\right)\right]
$$

Since unskilled workers do not require credit, their submarket equilibrium is independent of the loan market.

Under the assumption that there are skilled and unskilled workers in every cohort, the marginal worker who is just indifferent between the education options is given by

$$
U_{s}^{*}-U_{u}^{*}=e .
$$

As (10) in the static model, this condition equates the expected education cost $e+\ell_{0}$ to the expected skill premium, which is the difference between the first term in (17) (human wealth of a skilled person) and $U_{u}^{*}$. The observation that $U_{s}^{*}(0)>U_{s}^{*}\left(\rho^{E}-\rho^{U}>0\right)$ implies that uncontingent loans lead to more schooling:

Proposition 7 An economy with contingent loan contracts has less investment in human capital than an economy with uncontingent loan contracts.

We wish to compare the competitive search equilibrium to the allocation that a planner would choose who can dictate education and job creation. The planner's objective is to maximize the discounted value of output net of the costs of education and vacancy creation. He picks the number of skilled and unskilled vacancies that are created at every instant, $a_{s}$ and $a_{u}$, as well as the investment threshold $e$ so as to maximize

$$
\int_{0}^{\infty} e^{-r t}\left[p_{s} N_{s}+p_{u} N_{u}-\left(a_{s}+a_{u}\right) c-\delta H(e) \ell_{0}-\delta \int_{0}^{e} e^{\prime} d H\left(e^{\prime}\right)\right] d t .
$$

The numbers of employed and unemployed workers $\left(N_{k}\right.$ and $u_{k}$ for $\left.k=s, u\right)$ and 
the numbers of vacancies $\left(v_{k}\right.$ for $\left.k=s, u\right)$ evolve according to

$$
\begin{aligned}
\dot{N}_{s} & =u_{s} \lambda\left(q_{s}\right)-\delta N_{s}, \\
\dot{N}_{u} & =u_{u} \lambda\left(q_{u}\right)-\delta N_{u}, \\
\dot{u}_{s} & =H(e) \delta-\delta u_{s}-u_{s} \lambda\left(q_{s}\right), \\
\dot{u}_{u} & =[1-H(e)] \delta-\delta u_{u}-u_{u} \lambda\left(q_{u}\right), \\
\dot{v}_{s} & =a_{s}-u_{s} \lambda\left(q_{s}\right), \\
\dot{v}_{u} & =a_{u}-u_{u} \lambda\left(q_{u}\right) .
\end{aligned}
$$

We find that decentralized equilibria with uncontingent loans are optimal, i.e. they maximize the discounted value of output net of education and investment costs.

Proposition 8 The competitive search equilibrium with uncontingent loan contracts is equivalent to the social planner's solution.

Propositions 7 and 8 together show that contingent debt contracts lead to underinvestment in human capital. Given that unemployment reduces the expected repayment stream, workers have a preference for better-paid but riskier jobs. Anticipating this labor market outcome and the worse utilization of human capital, fewer people invest in education. This finding stands in contrast to the result of Moen (1998) who shows that, in a wage-bargaining framework with an exogenous number of firms, such contingent debt contracts can remove the holdup problem since workers can pass on a share of their education expenses to firms: if interest payments do not accrue in case of unemployment, they become part of the match surplus. However, adding a free entry condition to Moen's framework would destroy this result and would lead to similar conclusions as in our paper; higher wage demands of workers with contingent debt contracts reduce firm entry, which in turn worsens employment prospects and ultimately the incentives to invest in education.

\section{Conclusions}

Our analysis suggests that the amount of debt which an agent needs to finance his education, has a an influence on his labor market prospects. When applying 
for jobs, skilled workers take into account that labor market failure may lead to delayed repayments or even default which both reduce the effective debt burden. A ceteris paribus increase in the amount of debt raised can therefore be expected to affect both risk-bearing and observed wages. This has two interesting implications. First, the size of the loan and the repayment schedule associated with it influence expected as well as observed wages. Hence, the distribution of loan size among the population has a determining effect on the distribution of skilled wages and thus on residual inequality. This distribution in turn depends on the observed wealth distribution, since wealthier students require less external finance and loans. More wealth inequality translates into more wage inequality. On the other hand, the way in which education costs are shared between the government and individual families matters. If the public plays a more important role in financing higher education, fewer and smaller loans are required which reduces the variance of skilled wages. By contrast, a largely private education sector is likely associated with more wage dispersion.

Second, if government subsidies do not keep pace with growing education costs, poorer individuals require more external assistance to cover higher tuition fees or increased living costs. Our analysis predicts that this will lead to more risk exposure and higher wages. A large difference in the growth rates of schooling costs and student financial aid should then translate into an increased skill premium. This finding might explain why the widening of the wage gap by skills during the last two decades was much more pronounced in the US, where students bear a much larger share of increasing college prices, than in some European countries where the state plays a more active role in financing education.

Apart from covering education expenditures directly, some countries provide students with subsidized loans which enable the debtor to defer payments during unemployment spells without accumulating interest. Our model shows that this kind of "contingent debt contract" which allows to reduce the effective debt burden during unemployment periods likely provokes more risk-taking and less employment which in turn has a negative effect on the utilization of human capital and investment incentives. 


\section{References}

Acemoglu, D. (1996): "A Microfoundation for Social Increasing Returns in Human Capital Accumulation," Quarterly Journal of Economics, 111, 779804.

(2001): "Good Jobs versus Bad Jobs," Journal of Labor Economics, 19, $1-22$.

(2003): "Cross-Country Inequality Trends," The Economic Journal, $113,121-149$.

Acemoglu, D., And R. Shimer (1999a): "Efficient Unemployment Insurance," Journal of Political Economy, 107, 893-849.

- (1999b): "Holdups and Efficiency with Search Frictions," International Economic Review, 40, 827-928.

Benabou, R. (1996): "Heterogeneity, Stratification and Growth: Macroeconomic Implications of Community Structure and School Finance," American Economic Review, 86, 584-609.

Berentsen, A., G. Rocheteau, and S. Shi (2001): "Friedman Meets Hosios: Efficiency in Search Models of Money," forthcoming in The Economic Journal.

BovenberG, L., and B. Jacobs (2005): "Redistribution and Education Subsidies are Siamese Twins," Journal of Public Economics, 89, 2005-2035.

Burdett, K., S. Shi, and R. Wright (2001): "Pricing and Matching with Frictions," Journal of Political Economy, 109, 1060-1085.

Burdett, K., And E. Smith (2002): "The Low Skill Trap," European Economic Review, 46, 1439-1451.

Charlot, O., and B. Decreuse (2005): "Self-Selection in Education with Matching Frictions," Labour Economics, 12, 251-267.

Choy, S., and X. Li (2006): "Dealing With Debt: 1992-93 Bachelors Degree Recipients 10 Years Later," Discussion Paper NCES 2006-156, U.S. Department of Education, National Center for Education Statistics. 
Fernandez, R., and R. Rogerson (1996): "Income Distribution, Communities and the Quality of Public Education," Quarterly Journal of Economics, 111, 135-164.

Fuint, T. (1997): "Predicting Student Loan Defaults," Journal of Higher Education, 68, 322-354.

Galenianos, M., And P. Kircher (2007): "Directed Search with Multiple Job Applications," Working Paper, University of Pennsylvania.

Galor, O., and J. Zeira (1993): "Income Distribution and Macroeconomics," Review of Economic Studies, 60, 35-52.

Grout, P. (1984): "Investment and Wages in the Absence of Binding Contracts: a Nash Bargaining Approach," Econometrica, 52, 449-460.

Kircher, P. (2007): "Efficiency of Simultaneous Search," Working Paper, University of Pennsylvania.

Malcomson, J. (1999): "Individual Employment Contracts," in Handbook of Labor Economics, ed. by O. Ashenfelter, and D. Card, vol. 3, chap. 35. NorthHolland, Amsterdam.

Masters, A. (1998): "Efficiency of Investment in Human and Physical Capital in a Model of Bilateral Search and Bargaining," International Economic Review, 39, 477-494.

Moen, E. (1997): "Competitive Search Equilibrium," Journal of Political Economy, 105, 385-411.

_ (1998): "Efficient Ways to Finance Human Capital Investments," Economica, 65, 491-505.

- (1999): "Education, Ranking, and Competition for Jobs," Journal of Labor Economics, 17, 694-723.

Moen, E., And A. Rosen (2004): "Does Poaching Distort Training?" Review of Economic Studies, 71, 1143-1162. 
Montgomery, J. (1991): "Equilibrium Wage Dispersion and Interindustry Wage Differentials," Quarterly Journal of Economics, 106, 163-179.

Ortigueira, S. (2006): "Skills, Search and the Persistence of High Unemployment," Journal of Monetary Economics, 53, 2165-2178.

Rogerson, R., R. Shimer, and R. Wright (2005): "Search-Theoretic Models of the Labor Market: a Survey," Journal of Economic Literature, 43, 958988.

SHI, S. (2001): "Frictional Assignment, I. Efficiency," Journal of Economic Theory, 98, 232-260.

(2002): "A Directed Search Model of Inequality with Heterogeneous Skills and Skill-Biased Technology," Review of Economics Studies, 69, 467491.

\section{Appendix}

\section{Proof of Proposition 1:}

(a) Our assumption that skilled (unskilled) workers choose high-skill (low-skill) jobs allows us to solve both market segments separately. In what follows, we will prove existence and uniqueness of an equilibrium list $\left(\mathcal{W}_{s}, Q_{s}, U_{s}\right)$ for the skilled market. The corresponding analysis for unskilled workers is analogous and thus omitted.

Existence: For every worker type $\rho \in R$, let $w_{s}(\rho)>0$ and $0<q_{s}(\rho)<1$ be the unique solution of $\max _{w, q} \lambda(q)(w-\rho)$ s.t. the constraint $\varphi(q)\left(p_{s}-w\right)=$ $c$, i.e. the pair $\left(w_{s}(\rho), q_{s}(\rho)\right)$ is given implicitly by (8). We show that there is an equilibrium where $\mathcal{W}_{s}=\left\{w_{s}(\rho) \mid \rho \in R\right\}, U_{s}(\rho)$ is the maximum attainable utility given firms expect zero profits, and for any nonnegative wage $Q_{s}(w)=0$ if $\max \left\{w-\rho-U_{s}(\rho) \mid \rho \in R\right\}<0$ and $Q_{s}(w) \equiv \lambda^{-1}\left[\min \left\{U_{s}(\rho) /(w-\rho) \mid \rho \in R\right\}\right]$ otherwise.

For agents to maximize their utility, it must be the case that $Q_{s}\left(w_{s}(\hat{\rho})\right)=q_{s}(\hat{\rho})$ for every $\hat{\rho} \in R$. It is sufficient to prove that $\min \left\{U_{s}(\rho) /(w(\hat{\rho})-\rho) \mid \rho \in R\right\}=$ $U_{s}(\hat{\rho}) /(w(\hat{\rho})-\hat{\rho})$. Suppose this is not true, and $U_{s}(\hat{\rho}) /\left(w_{s}(\hat{\rho})-\hat{\rho}\right)>U_{s}(\tilde{\rho}) /\left(w_{s}(\hat{\rho})-\right.$ $\tilde{\rho})$ for some $\tilde{\rho} \neq \hat{\rho}$. Then, the matching probability $\lambda$ being decreasing in $q$ ensures 
$Q_{s}\left(w_{s}(\hat{\rho})\right)>q_{s}(\hat{\rho})$. Since $\left(w_{s}(\hat{\rho}), q_{s}(\hat{\rho})\right)$ implies zero expected profits for firms, $\varphi\left[Q_{s}\left(w_{s}(\hat{\rho})\right)\right]\left(p_{s}-w_{s}(\hat{\rho})\right)-c$ must be positive which is not compatible with profit maximization (Definition 1 (a)).

While our construction of $Q_{s}$ guarantees that the list $\left(\mathcal{W}_{s}, Q_{s}, U_{s}\right)$ satisfies optimal application (Definition $1(\mathrm{~b})$ ), we still need to show that profit maximization holds. Suppose there is a wage $\tilde{w}$ with the corresponding queue length $\tilde{q} \equiv Q_{s}(\tilde{w})$ for which $\varphi(\tilde{q})\left(p_{s}-\tilde{w}\right)-c>0$. Since $\tilde{q}$ must be positive, there exists a worker type $\tilde{\rho}$ with

$$
U_{s}(\tilde{\rho})=\lambda\left(q_{s}(\tilde{\rho})\right)\left(w_{s}(\tilde{\rho})-\tilde{\rho}\right)=\lambda(\tilde{q})(\tilde{w}-\tilde{\rho})
$$

Choose $\hat{q}<\tilde{q}$ such that $\varphi(\hat{q})\left(p_{s}-\tilde{w}\right)-c=0$. Since a shorter queue length increases worker utility,

$$
\lambda(\hat{q})(\tilde{w}-\tilde{\rho})>U_{s}(\tilde{\rho})
$$

which contradicts the fact that $\left(w_{s}(\tilde{\rho}), q_{s}(\tilde{\rho})\right)$ solves the constrained optimization problem of a $\tilde{\rho}$-worker.

Uniqueness: Under $\max \{\rho \in R\}<p_{s}-c$, there exists no equilibrium with $\mathcal{W}_{s}=\emptyset$. Otherwise, a firm could enter, offer a positive wage, attract an infinite queue and make positive profits.

Assume now that $\mathcal{W}_{s} \neq \emptyset$. We first show that any equilibrium set $\mathcal{W}_{s}$ must be a subset of $\left\{w_{s}(\rho) \mid \rho \in R\right\}$. Suppose $\hat{w}$ is an equilibrium wage but $\hat{w} \notin$ $\left\{w_{s}(\rho) \mid \rho \in R\right\}$. Profit maximization by firms requires $\hat{q} \equiv Q_{s}(\hat{w})>0$ and $\varphi(\hat{q})\left(p_{s}-\hat{w}\right)-c=0$. The equilibrium queue length being positive guarantees that, for one worker type, say $\hat{\rho}, \lambda(\hat{q})(\hat{w}-\hat{\rho})=U_{s}(\hat{\rho})$. It is easy to see that $(\hat{w}, \hat{q})$ must equal $\left(w_{s}(\hat{\rho}), q_{s}(\hat{\rho})\right)$. Suppose $(\hat{w}, \hat{q})$ is not the unique solution of $\max _{w, q} \lambda(q)(w-\hat{\rho})$ s.t. firms making zero profits: $\varphi(q)\left(p_{s}-w\right)-c=0$. Then the pair $\left(w_{s}(\hat{\rho}), q_{s}(\hat{\rho})\right)$ leads to higher worker utility, say $\hat{U}_{s}$, and firms still expect zero profits. Because of $w_{s}(\hat{\rho})-\hat{\rho}>\hat{U}_{s}>U_{s}(\hat{\rho}), Q_{s}\left[w_{s}(\hat{\rho})\right]$ must be strictly positive and greater than $q_{s}(\hat{\rho})$. If $\left(w_{s}(\hat{\rho}), q_{s}(\hat{\rho})\right)$ satisfies the firms' zero-profit constraint however, it must be the case that

$$
0=\varphi\left(q_{s}(\hat{\rho})\right)\left(p_{s}-w_{s}(\hat{\rho})\right)-c<\varphi\left[Q_{s}\left(w_{s}(\hat{\rho})\right)\right]\left(p_{s}-w_{s}(\hat{\rho})\right)-c
$$

which contradicts profit maximization. 
Finally, we prove that an equilibrium set $\mathcal{W}_{s}$ cannot be a strict subset of $\left\{w_{s}(\rho) \mid \rho \in\right.$ $R\}$. If this was the case, $w_{s}(\hat{\rho}) \notin \mathcal{W}_{s}$ for some $\hat{\rho} \in R$. Since expected firm profits are zero for any pair $\left(w, Q_{s}(w)\right)$ where $w$ is an equilibrium wage, it follows that $U_{s}(\hat{\rho})$, the maximum utility that a $\hat{\rho}$-type can achieve given $\mathcal{W}_{s}$ and $Q_{s}$, is strictly less than the utility generated by the pair $\left(w_{s}(\hat{\rho}), q_{s}(\hat{\rho})\right)$. Then however the equilibrium queue length for firms posting $w_{s}(\hat{\rho}), Q_{s}\left(w_{s}(\hat{\rho})\right)$, must strictly exceed $q_{s}(\hat{\rho})$. This once again contradicts profit maximization because longer queues are profitable for firms:

$$
0=\varphi\left(q_{s}(\hat{\rho})\right)\left(p_{s}-w_{s}(\hat{\rho})\right)-c<\varphi\left[Q\left(w_{s}(\hat{\rho})\right)\right]\left(p_{s}-w_{s}(\hat{\rho})\right)-c
$$

(b) Follows immediately from (8) and Assumption 1.

(c) To show that expected labor income is falling in $\rho$, differentiate $\lambda\left(q_{s}\right) w_{s}=$ $\varphi\left(q_{s}\right) p_{s} / q_{s}-c / q_{s}$ with respect to $q_{s}$ to obtain

$$
\left[\left(\varphi^{\prime}\left(q_{s}\right) q_{s}-\varphi\left(q_{s}\right)\right) p_{s}+c\right] \frac{1}{q_{s}^{2}} \frac{\partial q_{s}}{\partial \rho} .
$$

Equation (8) ensures that the term in square brackets equals $\left(\varphi^{\prime}\left(q_{s}\right) q_{s}-\varphi\left(q_{s}\right)\right) \rho$ which is negative for a strictly concave function $\varphi$. Since, according to part (b), $\partial q_{s} / \partial \rho>0$, the result follows.

The envelope theorem guarantees $\partial U_{s} / \partial \rho=-\lambda\left(q_{s}\right)<0$ and thus a negative relationship between $U_{s}$ and $\rho$.

\section{Proof of Proposition 4:}

(a) Maximizing (11) with respect to $e, q_{s}$ and $q_{u}$ yields the first-order conditions

$$
\begin{aligned}
\lambda\left(q_{s}\right) p_{s}-\lambda\left(q_{u}\right) p_{u}-c\left(\frac{1}{q_{s}}-\frac{1}{q_{u}}\right)-\ell_{0}-e & =0, \\
\lambda^{\prime}\left(q_{s}\right) p_{s}+\frac{c}{q_{s}^{2}} & =0, \\
\lambda^{\prime}\left(q_{u}\right) p_{u}+\frac{c}{q_{u}^{2}} & =0 .
\end{aligned}
$$

Because of $-q \lambda^{\prime}(q)=\varphi(q)-q \varphi^{\prime}(q),(20)$ coincides with the first equation in (7) and (19) coincides with the first equation in (8) for $\rho=0$. Hence, $q_{u}^{P}=q_{u}$ and $q_{s}^{P}=q_{s}(0)$. Because of $U_{s}(0)=\lambda\left(q_{s}(0)\right) p_{s}-c / q_{s}(0)$ and $U_{u}=\lambda\left(q_{u}\right) p_{u}-c / q_{u}$, equation (18) implies $e^{P}=U_{s}(0)-U_{u}-\ell_{0}=\bar{e}$.

(b) Since $H\left[I_{s}(\ell)-U_{u}-\ell_{0}\right]$ is declining in $\ell$ (Propositions 1 and 2 imply that $I_{s}$ is declining, and $H$ is assumed increasing) and since $\Lambda(0)<1$, the number 
of educated workers in the social optimum $E^{P}=H\left(e^{P}\right)$ is strictly larger than the number of educated workers in the competitive equilibrium of Proposition 3. Similarly,

$$
J_{s}^{P}=\frac{H\left(e^{P}\right)}{q_{s}^{P}}=\int_{0}^{\ell_{0}} \frac{H\left(e^{P}\right)}{q_{s}^{P}} d \Lambda(\ell)>\int_{0}^{\ell_{0}} \frac{H\left[I_{s}(\ell)-U_{u}-\ell_{0}\right]}{q_{s}(\rho(\ell))} d \Lambda(\ell)=J_{s},
$$

and $J_{u}^{P}=\left(1-H\left(e^{P}\right)\right) / q_{u}^{P}=\left(1-H\left(e^{P}\right)\right) / q_{u}<(1-E) / q_{u}=J_{u}$.

\section{Proof of Proposition 8:}

To solve the planner's problem we set up the current-value Hamiltonian

$$
\begin{gathered}
H=p_{s} N_{s}+p_{u} N_{u}-\left(a_{s}+a_{u}\right) c-\delta H(e) \ell_{0}-\delta \int_{0}^{e} e^{\prime} d H\left(e^{\prime}\right) \\
+\mu_{s}\left[u_{s} \lambda\left(q_{s}\right)-\delta N_{s}\right]+\mu_{u}\left[u_{u} \lambda\left(q_{u}\right)-\delta N_{u}\right] \\
+\alpha_{s}\left[H(e) \delta-\delta u_{s}-u_{s} \lambda\left(q_{s}\right)\right]+\alpha_{u}\left[[1-H(e)] \delta-\delta u_{u}-u_{u} \lambda\left(q_{u}\right)\right] \\
+\gamma_{s}\left[a_{s}-u_{s} \lambda\left(q_{s}\right)\right]+\gamma_{u}\left[a_{u}-u_{u} \lambda\left(q_{u}\right)\right]
\end{gathered}
$$

where the $\mu_{k}, \alpha_{k}$ and $\gamma_{k}$ denote the costate variables corresponding to $N_{k}, u_{k}$ and $v_{k}$ with $k=s, n$.

An interior steady state optimum must satisfy

$$
a_{k}^{P}=\underset{a_{k}}{\operatorname{argmax}} H \quad(k=s, n), e^{P}=\underset{e}{\operatorname{argmax}} H
$$

and

$$
\begin{aligned}
& \frac{\partial H}{\partial N_{s}}=r \mu_{s} \Rightarrow \mu_{s}=\frac{p_{s}}{r+\delta} \\
& \frac{\partial H}{\partial N_{u}}=r \mu_{u} \Rightarrow \mu_{u}=\frac{p_{u}}{r+\delta} \\
& \frac{\partial H}{\partial u_{s}}=r \alpha_{s} \Rightarrow(r+\delta) \alpha_{s}=\varphi^{\prime}\left(q_{s}\right)\left(\mu_{s}-\gamma_{s}-\alpha_{s}\right) \\
& \frac{\partial H}{\partial u_{u}}=r \alpha_{u} \Rightarrow(r+\delta) \alpha_{u}=\varphi^{\prime}\left(q_{u}\right)\left(\mu_{u}-\gamma_{u}-\alpha_{u}\right) \\
& \frac{\partial H}{\partial v_{s}}=r \gamma_{s} \Rightarrow r \gamma_{s}=\left[\varphi\left(q_{s}\right)-q_{s} \varphi^{\prime}\left(q_{s}\right)\right]\left(\mu_{s}-\alpha_{s}-\gamma_{s}\right) \\
& \frac{\partial H}{\partial v_{u}}=r \gamma_{u} \Rightarrow r \gamma_{u}=\left[\varphi\left(q_{u}\right)-q_{u} \varphi^{\prime}\left(q_{u}\right)\right]\left(\mu_{u}-\alpha_{u}-\gamma_{u}\right) .
\end{aligned}
$$

Since $H$ is linear in $a_{k}(k=s, n)$ and concave in $e$, the first-order conditions are also sufficient for a social optimum. Maximizing $H$ with respect to $a_{k}$ and $e$ 
yields

$$
\begin{aligned}
& \frac{\partial H}{\partial a_{s}}=0 \quad \Rightarrow \quad \gamma_{s}=c \\
& \frac{\partial H}{\partial a_{u}}=0 \quad \Rightarrow \quad \gamma_{u}=c \\
& \frac{\partial H}{\partial e}=0 \quad \Rightarrow \quad \ell_{0}+e=\alpha_{s}-\alpha_{u} .
\end{aligned}
$$

Some simple calculations show that $q_{s}$ and $\alpha_{s}$ following from (23) und (25) given (27) are identical to $q_{s}^{M}$ and $U_{s}^{*}+\ell_{0}$ for $\rho^{E}=\rho^{U}$. Similarly, the social planner's values of $q_{u}$ and $\alpha_{u}$ following from (24) and (26) given (28) are equivalent to $q_{u}^{M}$ and $U_{u}^{*}$. This guarantees that the social planner and the decentralized economy have the same education threshold $e$. 